\title{
Mediating Effects of Social Support in the Association Between Problems in Childhood and Adolescence and Well-Being in Adult Domestic Adoptees
}

\author{
Yolanda Sánchez-Sandoval ${ }^{1}$ (D) $\cdot$ Sandra Melero ${ }^{1} \cdot$ Ana María López-Jiménez $^{2}$
}

Published online: 4 May 2019

(C) The Author(s) 2019

\begin{abstract}
Research concerning adulthood and adoption has gained popularity in recent years, but there are very few studies involving positive variables of adjustment. Adopted people are believed to have more behavioral and emotional problems in childhood than the general population. Previous research suggests overall continuity of functioning in later life. However, certain variables might change that continuity. Through Structural Equation Modeling analyses, this paper assesses the mediating role of social support in the well-being of 70 adult adoptees. Findings showed a well-fitted model, where problems in adolescence had a direct effect on well-being in adulthood. Additionally, we found two mediating effects: (a) social support mediated the relationship between problems in adolescence and well-being later in life; and (b) problems in adolescence mediated the relationship between problems in childhood and well-being. The main implication of these results is that social support helps develop good levels of adjustment and well-being in adulthood. Taking all this into account, it is important for adoption professionals to encourage families to support their children and to provide additional support for those adoptees needing it.
\end{abstract}

Keywords Adult adoptees · Well-being $\cdot$ Social support · Behavioral and emotional problems $\cdot$ Childhood and adolescence

\section{Introduction}

Behavioral and emotional problems have been widely studied in adopted populations, but less research has been conducted on the opportunities of recovery and well-being. Traditionally, adoption has been analyzed from the viewpoint of the presence of problems, and the "bad seed myth" about adopted people has persisted: behavior is determined by genes and pre-adoptive experiences, and children adopted later in life will hardly recover

Yolanda Sánchez-Sandoval

yolanda.sanchez@uca.es

1 Department of Psychology, Faculty of Educational Sciences, Universidad de Cádiz, Avenida República Saharaui, s/n, Puerto Real, 11519 Cádiz, Spain

2 Department of Experimental Psychology, Universidad de Sevilla, Seville, Spain 
(Hartman and Laird 1990). On another hand, adoption is considered a measure to protect children at risk. It tries to provide a secure, healthy, and supportive context for children's development, and it has more long-term benefits than other measures used when these children cannot live with their birth families, like foster care (Del Pozo de Bolger et al. 2018). According to the conclusions of the systematic review performed by Melero and SánchezSandoval (2017), adoption seems to be a good way to improve children's adjustment. This work contributes to the second perspective, referring to the possibilities of developmental recovery in the context of adoption as a protective measure.

The main focus of research on adoption used to be childhood and adolescence. However, for some years, studies of adult adoptees have been gaining interest (Dekker et al. 2017; Grant et al. 2016; Greco et al. 2015; Levy-Shiff 2001; Westermeyer et al. 2014). Nevertheless, they also focused more frequently on the perspective of difficulties than on that of well-being.

Well-being is an extensive concept with many definitions. A broader definition of the term was provided by the UK Government:

[well-being] is understood as a positive physical, social and mental state; it is not just the absence of pain, discomfort and incapacity. It requires that basic needs are met, that individuals have a sense of purpose, that they feel able to achieve important personal goals, and that they participate in society. It is enhanced by conditions that include supportive personal relationships, strong and inclusive communities, good health, financial and personal security, rewarding employment, and a healthy and attractive environment (Defra 2008, p. 114).

According to Ryff (1989), well-being is more than the satisfaction of needs or the absence of illness. This concept is related to the term of eudaimonia, developed by Aristotle a long time ago, and is the result of the convergence of different theories and perspectives.

Ryff (1989) created a model of well-being on the basis of her research from different perspectives. This model included the six following dimensions: (1) Purpose in life includes life goals and feelings about meaning, purpose, and direction in one's life. (2) Autonomy refers to the one's self-view living according to personal convictions or influenced by social pressure. (3) Personal growth involves the extent to which one uses personal talents and potential to improve and grow as a person. (4) Environmental mastery is about management and control of different life situations and contexts. (5) Positive relationships concerns warm and trusting interpersonal connections with significant others. (6) Self-acceptance implies knowledge about, attitude towards, and acceptance of oneself, including limitations and feelings about past life.

Additionally, and related to well-being, Del Pozo de Bolger et al. (2018) developed the conceptual model of adjustment. These authors showed that there are some bio-behavioral and environmental risk factors - such as genetic predispositions, lack of pre-natal care, or history of maltreatment-associated with poor outcomes in adoptees. Adverse childhood experiences (ACEs), including maltreatment, have an important influence on well-being, both directly and added to other factors. Some adoptees come from early environments that adversely affect their subsequent development (Segatto and Ben 2013) have a higher likelihood of suffering from ACEs prior to their adoption.

Previous research found that ACEs are linked to the development of disorders and other health-related risks in childhood, adolescence, and adulthood (Kalmakis and Chandler 2015; Nurius et al. 2015). Prior research suggested that adults who experienced (physical or psychological) maltreatment during childhood tend to have lower levels of well-being in adulthood (Greenfield and Marks 2010). According to Nurius et al., ACEs are associated 
with poorer psychological health indicators that lead to other adversities in adulthood and decrease psychological well-being.

There are other theoretical models of well-being that, while not specifically about adoptees, might be useful to understand the heterogeneity of adjustment in adoption. According to Schulenberg et al. (2004), during childhood and adolescence, people establish a trajectory of functioning and adjustment that will probably continue to adulthood, including new roles and situations. In fact, in spite of using different measures, another recent study showed that prior psychopathological symptoms were one of the significant (negative) predictors of current subjective well-being, even considering the previous level of subjective well-being in the analysis (Jans-Beken et al. 2017). Another work found similar results: childhood problems had important influence on adulthood even after accounting for current diagnoses in adulthood (Copeland et al. 2015). Taking this possible continuity into account, adult adoptees who experienced more behavioral and emotional problems during childhood may have more difficulties and less well-being in adulthood. Additionally, according to Copeland et al. (2015), most psychiatric disorders are diagnosed in childhood, and this might affect their entire lives. Furthermore, there may be subthreshold problems that also affect well-being in adulthood. This occurs when children do not fulfill all the criteria for a certain disorder although they have some of the symptoms. However, these authors argued that optimal adult functioning is more than just psychiatric status.

In addition, Del Pozo de Bolger et al. (2018) included in their model some factors, such as the characteristics of the adoptive family (attachment, siblings, flexibility, etc.), relationship factors (with the adoptive and the birth family), and system factors (pre and postadoption services), that moderate the outcomes. In fact, some studies showed that cohabitation in a healthy, positive, and protective family has important and positive effects on the recovery of initial delays in adopted children and in the promotion of well-being (Juffer et al. 2011; Segatto and Ben 2013). Studies with non-adoptive samples have shown family influences to have a key role in child and adolescent development (Fuentes et al. 2011; Steinberg 2001). The family has an impact not only on child wellbeing, but also on a broad of developmental outcomes; for example, internalization of values (Grusec and Goodnow 1994), substance abuse (Riquelme et al. 2018), or self-concept (Martínez et al. 2019). The influence of family context during childhood and adolescence have important long-term consequences during adulthood, as shown in studies with young adults (Aquilino and Supple 2001; Garcia et al. 2018).

Social support is also a significant and positive predictor of all the dimensions of psychological well-being, and it seems that its influence is similar in males and females (Keresteš et al. 2012). According to Feeney and Collins (2015), social support can be conceptualized as an interactive process that includes two main functions: being a source of strength and a relational catalyst. The first function refers to the encouragement of thriving in spite of adverse situations and the emergence from such situations. The purpose of social support as a relational catalyst is to promote the participation in opportunities for exploration and development in non-adverse contexts. It is important to distinguish between received and perceived social support which, although related, are not the same. Perceived support is more abstract and subjective, whereas received support is more tangible and objective (Uchino 2009). According to Uchino (2009), perceived support has important influence on health and well-being and it is influenced, in turn, by other factors like support seeking or optimism. This author stated that people with a positive family environment in childhood may develop more positive psychological profiles in their subsequent life stages. These profiles include better perceived support, social skills, and other factors like self-esteem. Additionally, it is important to take into account that social support 
has two possible origins: natural and formal systems. Natural support is related to family and friends and is more stable. In contrast, formal support comes from professionals and is more temporary (Hogan et al. 2002).

Perceived social support is considered a protective factor against negative events (Cohen 2003 cited by Tan et al. 2018). In addition, the Self Determination Theory stated that wellbeing is expected to improve with social support (Deci and Ryan 1985 cited by Dağ and Şen 2018). The mediating role of social support has been studied for a long time. A study performed more than 20 years ago, found a mediating effect of social support considering the relation between maltreatment in childhood and adjustment in adulthood (Runtz and Schallow 1997). Nowadays, several works are studying social support mediation between different variables: family violence and aggression in adolescents (Agbaria and Natur 2018), internal locus of control and psychological symptoms in young adults (Dağ and Şen 2018), relative income and suicide in adults (Zhou et al. 2018), or extraversion and happiness (Tan et al. 2018). According to prior literature, social support may be a direct predictor of adult outcomes (Taylor et al. 2014) or have a direct or indirect effect on health problems during adulthood (Herrenkohl et al. 2016). On the contrary, previous research showed that social support from family and friends moderates the effects of ACEs, like sexual abuse (Murthi and Espelage 2005), in subsequent development. However, results concerning moderation received limited support and just a few of them were theoreticallybased (Grant et al. 2006).

The current study analyzes the relation between adoptees' difficulties in childhood and adolescence and adult well-being from a longitudinal perspective. The aim of this work is to test a theoretical structural model, proposing a direct effect of childhood and adolescent behavioral and emotional problems on adult psychological well-being, as well as the mediating effect of perceived social support in that relation (see Fig. 1). This model draws on the contributions of authors such as Copeland et al. (2015) and Herrenkohl et al. (2016), among others although most of their contributions have either referred to samples of nonadopted people or other indicators of adjustment.

According to the model (see Fig. 1), problems at Wave 1 (W1, around 22 years ago) and problems at Wave 2 (W2, around 16 years ago) have a direct effect on adult psychological well-being. In addition, current perceived social support (at W3) would exert a mediating role on the relation between previous problems (W2) and current psychological well-being. In other words, emotional and behavioral problems when participants were children and adolescents would directly and negatively affect the adult psychological well-being, and these relations would be indirectly and negatively influenced by social support. Problems

Problems in

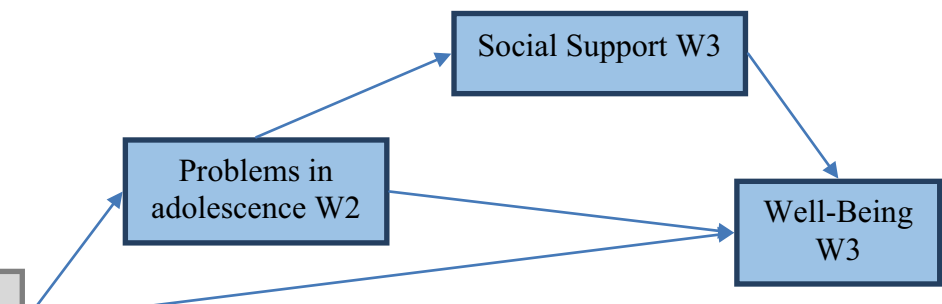
childhood W1

Fig. 1 Hypothetical model 
at Wave 1 would have a direct and positive effect on problems at Wave 2. Therefore, the higher the scores on emotional and behavioral problems in adopted children, the higher the difficulties in adolescents, and the lower the scores of psychological well-being in adult adoptees. However, the effect of previous difficulties on future psychological well-being will depend on current perceived social support.

\section{Methods}

\subsection{Participants}

The group of participants in this study included 70 Spanish young adult adoptees $(50 \%$ women). They are part of a group of families taking part in a longitudinal study of adoption in Andalusia (Spain), which is now on its third wave. This project started more than 20 years ago, with families who adopted their children between 1987 and 1994. All those children were adopted domestically from care; they were not international adoptions. Wave 1 was assessed in $1995(n=394)$, when the children had been living with their adoptive parents for an average of 6 years. Wave 2 took place in $2001(n=273)$, and Wave 3 in 2016-2017. In this work, we analyze the results of participants who completed all the protocols of the three waves of the study.

The mean age of the sample is 28.84 years ( $S D=3.61$, age range: $25-43$ years). A few participants (12.9\%) had some kind of disability (1.4\% physical, 5.7\% sensory, and $5.7 \%$ mental disability). The interviews with three of the participants took place accompanied by one of the adoptive parents, who aided a better understanding between the adoptee and the interviewer. Concerning age at adoption, most of the children were adopted before their first birthday $(M=2.06$ years, $S D=3.24)$. At the moment of the assessment, $25.7 \%$ were still studying, and $55.7 \%$ were working, and $41.4 \%$ were still living with their parents. Many participants were involved in stable relationships (70\%) and some of them had children $(30 \%)$.

\subsection{Measures}

Psychological Well-Being Scales (Ryff and Keyes 1995). We used a short Spanish validated version of the instrument developed by Díaz et al. (2006). This scale assesses different components of well-being with 29 items rated on a six-point Likert scale, ranging from 1 (Completely disagree) to 6 (Completely agree). This instrument provides a global mean score (from 1 to 6 ) and it also has six subscales, corresponding to the six components of well-being described above: Self-acceptance (e.g. "When I look at the story of my life, I am pleased with how things have turned out"), Positive relationships with others (e.g. "I know that I can trust my friends, and they know they can trust me"), Autonomy (e.g. "I am not afraid to voice my opinions, even when they are in opposition to the opinions of most people"), Environmental mastery (e.g. "In general, I feel I am in charge of the situation in which I live"), Purpose in life (e.g. "I enjoy making plans for the future and working to make them reality"), and Personal growth (e.g. "I have the sense that I have developed a lot as a person over time"). This instrument has been widely used since its development. It has been translated into more than 30 different languages (Ryff 2014) and the model has been confirmed in non-Anglo-Saxon cultures, like the Spanish and the Colombian (van Dierendonck et al. 2008). In this work, only the global mean score will be used, because we are 
interested in overall psychological well-being. Ryff and Keyes (1995), through a confirmatory factor analysis, showed that a second-order single factor has better adjustment than the six-factor model. This might be explained because of the high correlations between the dimensions of the instrument. In the present study, the measure shows a Cronbach's alpha of .90 for the global score and ranging from .60 to .82 for the subscales.

Duke-UNC Functional Social Support Questionnaire (Broadhead et al. 1988). We used the Spanish version validated by Bellón Saameño et al. (1996). It assesses self-perceived social support, using 11 items rated on a Likert scale ranging from 1 (much less than I would like) to 5 (as much as I would like). The scale provides a global score through the summation of all items. In addition, it has two subscales: confident support, and affective support. The confident subscale measures perceived support as a source of strength (e.g. "I get chances to talk to someone I trust about my personal and family problems"), and the affective subscale assess it as a relational catalyst (e.g. "I get invitations to go out and do things with other people"). The reliability of this measure is excellent in the present study, with a Cronbach's alpha of .90 in the global scale, .86 in the confident support subscale, and .79 in the affective support subscale.

Revised Rutter Parent Scale (RRPS) (Hogg et al. 1997). This was used in Waves 1 and 2 to assess the presence of problems in adopted children. The instrument provides a global score of problems and scores in different subscales: Behavioral problems (e.g. "Is often disobedient"), Emotional problems (e.g. "Appears miserable, unhappy, tearful or distressed"), Hyperactivity problems (e.g. "Cannot settle to anything for more than a few moments") and problems in Prosocial behavior (e.g. "Tries to be fair in games"). Every one of the 50 items reflects different problematic behaviors, and parents had to rate their frequency using the scale: 0 (never), 1 (sometimes), or 2 (very frequently). In this case, we used the global mean score in both waves. This measure showed a good level of reliability both at W1 and W2. Cronbach's alpha for the global score at W1 was .81 (between .66 and .72 for the subscales), and at W2 the global score showed an alpha of .86 (between .66 and .83 for the subscales).

\subsection{Procedure}

This study started in 1995 with a group of families $(n=394)$, taking part in Wave 1 . Then, in 2001, a large group of those families was contacted $(n=273)$ and participated in Wave 2. Recently, for Wave 3, they were contacted again. In this case, with the permission of the public administration, authors sent a letter to every family that participated in Wave 2 . Subsequently, a component of the team phoned every family, requesting the participation of their adult adopted children.

There were some attritions between Waves 2 and 3 because some people refused to participate and some could not be located. Attrition was examined to determine whether it was systematic in relation to any variable. In the first place, we analyzed whether participants in Wave 3 had different characteristics than those who did not participate in that wave. We found that participants in Wave 3 were similar to participants in Wave 1 in all of the known sociodemographic characteristics: proportion of males and females, $\chi^{2}(1)=.303$, $p>.05$; age at adoption, $t(391)=.555, p>.05$; multiple adoption, $\chi^{2}(1)=.073, p>.05$ ethnicity, $\chi^{2}(1)=.934, p>.05$; presence of disabilities, $\chi^{2}(1)=.998, p>.05$; severity of initial problems, $\chi^{2}(3)=1.809, p>.05$, family's educational level, $\chi^{2}(2)=.181, p>.05$; time of institutionalization, $\chi^{2}(2)=2.614, p>.05$; drug dependency of biological parents, $\chi^{2}(1)=2.104, p>.05$; presence of maltreatment prior to adoption, $\chi^{2}(1)=2.480, p>.05$; 
two or one-parent family structure, $\chi^{2}(1)=.480, p>.05$, or family satisfaction with adoption, $t(373)=-1.521, p>.05$. More information about satisfaction with adoption measure can be seen in Sánchez-Sandoval (2011).

We then compared measures of adjustment from Waves 1 and 2 between those who took part in Wave 3 and those who did not. Regarding the Rutter Revised Parent Scale (Hogg et al. 1997), there were no significant differences between participants and nonparticipants in Wave 3: total problems (Wave 1: $t[155.122]=-.390, p>.05$; Wave 2: $t[259]=-.290$, $p>.05$ ); emotional problems (Wave 1: $t[154.769]=-.383, p>.05$, Wave $2: t[259]=.331$, $p>.05$ ); hyperactivity (Wave $1: t[271]=1.327, p>.05$; Wave $2: t[259]=.203, p>.05$ ); behavioral problems (Wave 1: $t[271]=-.164, p>.05$; Wave 2: $t[259]=.158, p>.05$ ); and problems in prosocial behavior (Wave 1: $t[163.099]=-1.281, p>.05$; Wave 2: $t[259]=-1.703, p>.05$ ). Self-esteem (Rosenberg 1965) and Life Satisfaction (Huebner 1991) were also analyzed concerning attrition. Participants in Wave 3 were not different from nonparticipants in any of these two domains in Wave 2, specifically in their adolescence, $t(54.338)=-.342, p>.05$ and $t(88)=1.062, p>.05$, for self-esteem and life satisfaction, respectively. More information about these measures can be seen in SánchezSandoval (2015).

If the adult adoptees accepted being interviewed, we established an appointment to interview them and complete the protocols either at their homes or some other place, if the participant so desired. Completing the entire interview and the instruments required one to $2 \mathrm{~h}$. If a visit was not possible, other forms were considered, including: sending the protocols through postal or electronic mail, interviewing the participant by phone or performing the interviews through Skype.

Concerning ethical implications, every participant signed their informed consent before being interviewed. The study was approved by the Bioethics Committee of the authors' university.

\subsection{Data Analysis}

First, we performed an analysis of correlations between the variables. The purpose of that analysis was to determine whether any variables should be deleted due to correlations with an absolute value greater than .7 (multicolinearity problems) or lower than .2 (low correlation). In this case, none of the included variables fulfilled those criteria, so none of them was deleted from the subsequent model.

LISREL software, version 8.71, was used to estimate the model with structural equation modeling (SEM), using the maximum likelihood method. Baron and Kenny (1986), established some conditions that have to be fulfilled for mediation using SEM: (1) the predictor is significantly related to the criterion variable, (2) the predictor is significantly associated to the mediator, (3) the mediator is significantly connected to the criterion variable, and (4) the variance is reduced when the mediator is controlled. According to MacKinnon et al. (2007), the first condition reduces the power to detect mediation. These authors stated that, in some cases, significant mediation exists but the relation between $\mathrm{X}$ and $\mathrm{Y}$ is not significant, especially in multiple mediator models where inconsistent mediation might occur. For this analysis, an initial hypothetical model was proposed (see Fig. 1) based on various previous theoretical contributions. It was subsequently tested and modified according to the coefficients, and non-significant direct effects were deleted. 
Table 1 Correlations and mean scores of scales

\begin{tabular}{lllll}
\hline & $\begin{array}{l}\text { Problems in } \\
\text { childhood W1 }\end{array}$ & $\begin{array}{l}\text { Problems in ado- } \\
\text { lescence W2 }\end{array}$ & $\begin{array}{l}\text { Social Sup- } \\
\text { port W3 }\end{array}$ & Well-Being W3 \\
\hline Problems in childhood W1 & 1 & & & \\
Problems in adolescence W2 & $.55^{* *}$ & 1 & 1 & 1 \\
Social support W3 & -.09 & $-.30^{*}$ & $.69^{* *}$ & 4.67 \\
Well-being W3 & -.18 & $-.45^{* *}$ & 45.13 & .82 \\
Mean & .52 & .46 & 8.78 & .22 \\
SD & .20 & & & \\
\hline
\end{tabular}

$\mathrm{W} 1=$ Wave $1 ; \mathrm{W} 2=$ Wave $2 ; \mathrm{W} 3=$ Wave 3

$* p<.05, * * p<.01$

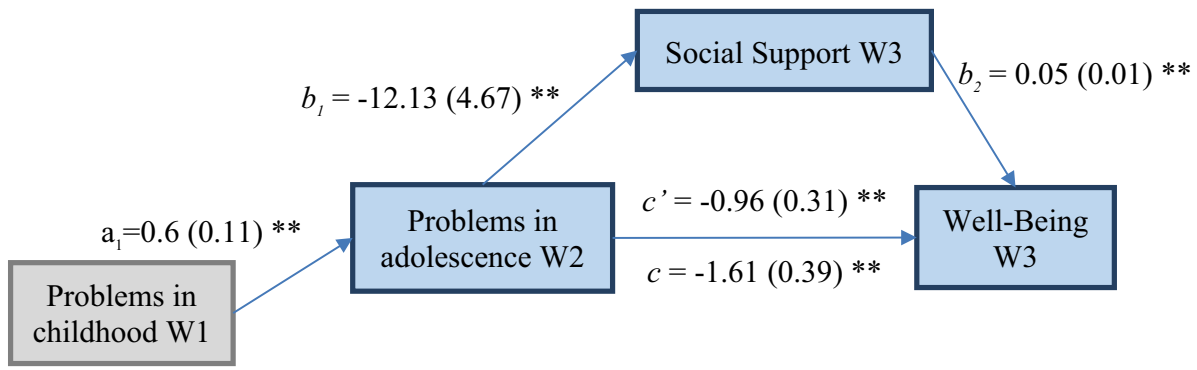

Fig. 2 Mediating effect of problems in adolescence and social support in the relation between problems in childhood and adult well-being. Note: $* *=p<.01$; all presented effects are unstandardized; $a_{1}$ is the direct effect of problems in childhood on problems in adolescence; $b_{1}$ is the effect of problems in adolescence on social support; $b_{2}$ is the effect of social support on well-being; $c$ ' is the direct effect of problems in adolescence on well-being, and $c$ is the total effect of problems in adolescence on well-being

\section{Results}

\subsection{Preliminary Descriptive Analysis}

Table 1 displays the means, standard deviations, and correlations between the variables in the study's estimated model. As expected, positive significant correlations were found between behavioral and emotional problems in childhood (W1) and problems in adolescence (W2). Additionally, problems at W2 were negatively correlated with psychological well-being in adulthood (W3). However, no significant correlation was observed between problems at W1 and psychological well-being at W3 $(r=-.18, p>.05)$. Lastly, social support was negatively correlated with problems at W2, and positively correlated with psychological well-being at W3.

\subsection{Model Testing}

In accordance with the strategy used, the adjusted model is presented in Fig. 2. The measures of error are not included in the Figure although they were also estimated. This model showed satisfactory fit to the data as shown by the measures of goodness of fit included in Table 2. The tested model has a good fit taking into account the Chi square value, as 
Table 2 Goodness of fit measures for the structural model

\begin{tabular}{|c|c|c|c|c|c|c|c|}
\hline \multirow[b]{2}{*}{ Goodness-of-fit measures } & \multicolumn{3}{|c|}{ Absolute fit measures } & \multicolumn{4}{|c|}{ Incremental fit measures } \\
\hline & $\mathrm{MFF}-\chi^{2}$ & $\chi^{2}$ & RMSEA & NFI & NNFI & CFI & IFI \\
\hline Collected values & $.73(p=.70)$ & $.72(p=.70)$ & $.00(p=.74)$ & .99 & 1. & 1 & 1 \\
\hline Recommended values & & & $<.08$ & $>.90$ & $>.90$ & $\approx 1$ & $\approx 1$ \\
\hline
\end{tabular}

CFI comparative fit index; IFI incremental fit index; $M F F$ minimum fit function; $N F I$ normed fit index; $N N F I$ non-normed fit index; RMSEA root mean square residual

well as the RMSEA, both lower than .06. The values of the incremental goodness of fit indices (NFI, NNFI, CFI, and IFI) were above .90. As shown in Fig. 2, the effects between the following variables were statistically significant: problems in childhood and problems in adolescence $[B=.60(.11), p<.01]$, problems in adolescence and social support-W3 $[B=-12.13$ (4.67), $p<.01]$, problems in adolescence and well-being-W3 $[B=.96(.31)$, $p<.01]$, and social support-W3 and well-being-W3 $[B=.05(.01), p<.01]$.

It was predicted that behavioral problems at W1 (RRPS1) would have a direct effect on well-being at W3. However, as shown in Table 3, the only effect concerning these variables that was confirmed in the model was indirect, through problems at W2 $1100 \%$ of the effect of problems in childhood on well-being-W3 was indirect because of its association with problems in adolescence). As expected, problems at W2 (RRPS2) had a direct, negative, and significant effect on well-being-W3 (59.63\% of the total effect of problems in adolescence on well-being-W3), and an indirect effect (partial mediation) through social support at W3 (40.37\% of the total effect of problems in adolescence on well-being).

\section{Discussion}

The purpose of this study was to validate a model of the relation between behavioral and emotional problems in childhood and adolescence, and their well-being in adulthood in people who were adopted. In addition, we aimed to test the mediating role of social support

Table 3 Direct and indirect effects of problems in childhood and problems in adolescence over adult wellbeing: coefficients, errors, significance and effects percentage

\begin{tabular}{|c|c|c|c|c|}
\hline & $\mathrm{B}$ & SE & $\mathrm{t}$ & $\%$ \\
\hline Total effect of Problems in adolescence on well-being $(c)$ & -1.61 & 0.39 & $-4.18 * *$ & 100 \\
\hline Direct effect $\left(c^{\prime}\right)$ & -0.96 & 0.31 & $-3.13 * *$ & 59.63 \\
\hline Indirect effect $1\left(c-c^{\prime}\right)=(-1.61)-(-0.96)$ & -0.66 & 0.27 & $-2,44 * *$ & 40.37 \\
\hline $\begin{array}{l}\text { Total indirect effect of Problems in childhood on well-being } \\
\text { Indirect effect } 2\left(a_{1} * c^{\prime}\right): 0.6^{*}-0.96\end{array}$ & -0.97 & 0.29 & $-3.30 * *$ & 100 \\
\hline $\begin{array}{l}\text { Problems in childhood } \rightarrow \text { problems in adolescence } \rightarrow \text { well-being } \\
\text { Indirect effect } 3\left(a_{1} * b_{1} * b_{2}\right): 0.6 *-12.13 * 0.05\end{array}$ & -0.58 & 0.21 & $-2.69 * *$ & 61.28 \\
\hline $\begin{array}{l}\text { Problems in childhood } \rightarrow \text { problems in adolescence } \rightarrow \text { social sup- } \\
\text { port } \rightarrow \text { well-being }\end{array}$ & -0.36 & 0.17 & $-2.12 *$ & 38.72 \\
\hline
\end{tabular}


for outcomes in adulthood. Findings of this work largely corroborate the initially proposed model, showing direct and indirect effects between these variables and the partial mediating role of perceived social support. In the initial model, we proposed that adopted children's difficulties at Wave 1 would have negative direct effects on their well-being during young adulthood. This relation was not verified. However, the model does confirm that those initial problems have an indirect effect on psychological well-being in adults through the same variable measured at W2 and perceived social support.

In other words, the greater or lesser difficulties, identified by the adoptive families in their children during the first years (W1), do not determine directly their psychological adjustment about 20 years later, as adults. Despite that early adversity is a risk for psychological well-being (Greenfield and Marks 2010; Keyes et al. 2012; Lee and Chen 2017; van der Vegt et al. 2009), the quality of the subsequent context has been shown to be very important. For instance, McGoron et al. (2012) found that the quality of attachment with the new caregivers is a protective factor against the presence of psychopathology at early ages. Likewise, other research shows that, at later ages, adolescence or emerging adulthood, good family relationships may be a protective factor for later adjustment of adoptees, lessening the negative influence of pre-adoptive stressors (Balenzano et al. 2018). This finding allows us to understand the remarkable potential for recovery in children's development, as other studies with adoptive samples have shown (Juffer et al. 2011; Palacios et al. 2014; Segatto and Ben 2013).

However, this work shows that initial difficulties (W1) have an indirect effect on adult well-being (W3) through problems in adolescence, and also this closer adversity has a direct effect on adult well-being. In line with this, children's problems during the first years of cohabitation have a direct effect on subsequent problems. The trend is for greater problems at W1 to present greater problems at W2. Other studies showed that psychopathological symptoms or difficulties in psychological adjustment are sustained over time (Grotevant et al. 2011). However, a previous work with this sample indicated a decrease in difficulties throughout the years (Sánchez-Sandoval 2002), but it was found that children with higher levels of behavioral and emotional difficulties at the beginning of cohabitation seemed to display more vulnerability for difficulties later on. In addition, families that observe fewer behavioral problems in their children during the first years of adoption are more likely to continue rating their behavior as more adaptive (Sánchez-Sandoval 2011). So, the problems related to children's behavior are one of the variables that explain stress in adoptive parenthood and hinder family relationships, as previous research revealed (Sánchez-Sandoval and Palacios 2012). Probably, those findings identify a subgroup of adoptive families that encountered more initial difficulties in their children and needed more external support to deal with them.

In this regard, it is important to take ACEs into account because they are related to the development of disorders at subsequent stages (Kalmakis and Chandler 2015; Nurius et al. 2015). According to Kendall-Tackett (2002), there are four pathways that influence later development, in this case, in victims of ACEs: (1) Firstly, the behavioral pathway, which makes it more likely for individuals to perform high risk activities like substance consumption or sexual risk behaviors. (2) Secondly, the social pathway, which may affect their wellbeing through the lack of support, which, in turn, may lead to homelessness or revictimization. (3) Thirdly, the cognitive pathway, which comprises attitudes and beliefs, such as an internal working model of powerlessness or poor health perception. (4) Finally, the emotional pathway, which leads to greater risk of depression in people who experienced ACEs and also increases vulnerability to other risk conditions and to a higher likelihood of posttraumatic stress disorder, which could lead to other problems. 
The final model corroborates the theoretical relation between adjustment at W2 and psychological well-being at W3. In other words, problems in adolescence have a direct negative effect on psychological well-being 16 years later, so more recent adversities have an influence on adult well-being and there is a partial mediation considering initial difficulties. These behavioral, emotional, and social difficulties of adolescent adoptees are a risk factor for their well-being in early adulthood (Copeland et al. 2015). In fact, as stated by JansBeken et al. (2017), prior psychopathological symptoms negatively predict current subjective well-being, supporting the idea that the trajectory of functioning and adjustment starts in childhood and adolescence, and it probably continues during adulthood (Schulenberg et al. 2004). Nevertheless, the study of adoptive families allows us to analyze changes on this trajectory. In this regard, the current study shows that, despite initial difficulties, it is possible to achieve adequate adult adjustment.

This study advances our knowledge of a particular protective factor for psychological well-being in adulthood. Perceived social support mediates the effects of difficulties at W2 on adult well-being. Previous research showed that social support has an important influence on health and adjustment (Uchino 2009). High levels of perceived social support attenuate the effects of difficulties at W2 on adult well-being. Previous research showed a positive direct relation between social support and adult development (Taylor et al. 2014), as well as an indirect or mediator effect on the relation between previous and later problems (Herrenkohl et al. 2016). The presence of this mediating variable in the model leads to the conclusion that perceived difficulties at the beginning of an adoption do not directly determine adult development, but there is an indirect influence through more recent difficulties. Adequate levels of support attenuate those difficulties, allowing the adoptees to achieve good levels of well-being and adjustment in adulthood, despite their problems at previous developmental stages.

\subsection{Strengths and Limitations}

This research allows us to draw conclusions about the continuity of development throughout the life span. Its longitudinal design allows analyzing the relation between psychological well-being during the first decades of adulthood, and the existence of more or fewer behavioral and emotional difficulties in people who were adopted about 20 and 15 years ago.

The present study has some limitations that should be taken into account. One of these limitations is the number of participants in the sample. However, other studies of adult adoptees used similar sample sizes (Dekker et al. 2017; Oke et al. 2015). The characteristics of the study made it difficult to locate and access some of the participants from previous waves, and some participants decided not to take part. Despite the small number of participants, this sample is comparable to the initial one (W1) according to the analysis of attrition of the longitudinal design.

Another limitation is the use of self-report measures that may introduce several sources of bias in the obtained results. However, these measures have been widely used in previous research. Another important thing to consider is the categorization of support in this study. In this case, a measure of perceived social support was used instead of a received social support measure. The same participant could score differently in the two kinds of social support, but perceived social support is more important in relation to psychological wellbeing outcomes (Feeney and Collins 2015). 


\subsection{Implications}

Taking all into account, adoption should be considered as an adequate solution because it gives the opportunity to all involved to positively change their lives. However, some situations require support from professionals (Segatto and Ben 2013). Some adult adoptees may have experienced diverse problems or difficulties, including unsuccessful relationships with others. Hence, it is important to help them to recover from the emotional consequences of those problems (Herrenkohl et al. 2016). Considering the findings of our work, we suggest the need to articulate professional specialized services for adult people who went through the childhood protective system.

From the beginning, adoptive families should receive the additional support they need to bring up their children. During the first moments, through different activities, adoption teams must support the development of the bond between the child and his/her adoptive family (Segatto and Ben 2013). The establishment of that bond is really essential for subsequent development because families become a source of support. Due to the relevant role of social support in children's development, its use prevention and treatment of difficulties should also be taken into account (Herrenkohl et al. 2016). Thus, professionals who intervene in social support must attend to the environment surrounding the person, which may include stressors. Social support interventions are normally applied to people who already have problems (Uchino 2009). Concerning the overall continuity of problems, subthreshold cases in childhood should be identified and treated because this might prevent future disorders or damage in adulthood (Copeland et al. 2015).

An alternative is to focus also on prevention, or on the improvement of social skills (Hogan et al. 2002), and apply interventions to children and adolescents-even to adultsto help them to improve their networks (Uchino 2009). According to Hogan et al. (2002), this kind of interventions may have long-term effects on the natural sources of support and consequently increase perceived social support (Hogan et al. 2002). In addition, prevention strategies should include the maintenance of the individuals' context and the consolidation of their social networks to promote positive coping (Herrenkohl et al. 2016).

Acknowledgements This work was supported by the Ministerio de Economía y Competitividad of the Spanish Government [Project PSI2014-52336-R, Young Adult Adoptees' Psychological Adjustment and Developmental Tasks: a 20-year follow-up and keys for intervention], and a fellowship granted to Sandra Melero by University of Cádiz to finance her Ph.D. formation process.

\section{Compliance with Ethical Standards}

Conflict of interest The authors declare that they have no conflict of interest.

Human and Animal Participants The research involved human participants and included an informed consent. This research has the approval of the Bioethics Committee of the University of Cadiz (Spain).

Informed consent Every participant signed the informed consent form prior the interviews, following the ethical guidelines of the University of Cadiz.

Open Access This article is distributed under the terms of the Creative Commons Attribution 4.0 International License (http://creativecommons.org/licenses/by/4.0/), which permits unrestricted use, distribution, and reproduction in any medium, provided you give appropriate credit to the original author(s) and the source, provide a link to the Creative Commons license, and indicate if changes were made. 


\section{References}

Agbaria, Q., \& Natur, N. (2018). The relationship between violence in the family and adolescents aggression: The mediator role of self-control, social support, religiosity, and well-being. Children and Youth Services Review, 91, 447-456. https://doi.org/10.1016/j.childyouth.2018.06.016.

Aquilino, W. S., \& Supple, A. J. (2001). Long-term effects of parenting practices during adolescence on well-being outcomes in young adulthood. Journal of Family Issues, 22(3), 289-308. https://doi. org/10.1177/019251301022003002.

Balenzano, C., Coppola, G., Cassibba, R., \& Moro, G. (2018). Pre-adoption adversities and adoptees' outcomes: The protective role of post-adoption variables in an Italian experience of domestic open adoption. Children and Youth Services Review, 85, 307-318. https://doi.org/10.1016/j.childyouth .2018.01.012.

Baron, R. M., \& Kenny, D. A. (1986). The moderator-mediator variable distinction in social psychological research: Conceptual, strategic, and statistical considerations. Journal of Personality and Social Psychology, 51(6), 1173-1182. https://doi.org/10.1037/0022-3514.51.6.1173.

Bellón Saameño, J. A., Delgado Sánchez, A., Luna del Castillo, J. D., \& Lardelli Claret, P. (1996). Validity and reliability of the Duke-UNC-11 questionnaire of functional social support. Atencion Primaria/ Sociedad Espanola de Medicina de Familia y Comunitaria, 18(4), 153-156,158-163. Retrieved from http://europepmc.org/abstract/MED/8962994. Accessed 2 June 2016.

Broadhead, W. E., Gehlbach, S. H., de Gruy, F. V., \& Kaplan, B. H. (1988). The Duke-UNC functional social support questionnaire. Measurement of social support in family medicine patients. Medical Care, 26(7), 709-723.

Cohen, S. (2003). Psychological models of the role of social support in the etiology of physical disease. In P. Salovey \& A. J. Rothman (Eds.), Social psychology of health (pp. 227-244). New York, NY: Psychology Press.

Copeland, W. E., Wolke, D., Shanahan, L., \& Costello, J. (2015). Adult functional outcomes of common childhood psychiatric problems a prospective, longitudinal study. JAMA Psychiatry, 72(9), 892-899. https://doi.org/10.1001/jamapsychiatry.2015.0730.

Dă̆ İ., \& Şen, G. (2018). The mediating role of perceived social support in the relationships between general causality orientations and locus of control with psychopathological symptoms. Europe's Journal of Psychology, 14(3), 531-553. https://doi.org/10.5964/ejop.v14i3.1563.

Deci, E. L., \& Ryan, R. M. (1985). The general causality orientations scale: Self-determination in personality. Journal of Research in Personality, 19, 109-134. https://doi.org/10.1016/0092-6566(85)90023-6.

Defra. (2008). Sustainable development indicators in your pocket 2008. London: Defra.

Dekker, M. C., Tieman, W., Vinke, A. G., van der Ende, J., Verhulst, F. C., \& Juffer, F. (2017). Mental health problems of Dutch young adult domestic adoptees compared to non-adopted peers and international adoptees. International Social Work, 60(5), 1201-1217. https://doi.org/10.1177/0020872816 651699.

Del Pozo de Bolger, A., Dunstan, D., \& Kaltner, M. (2018). A conceptual model of psychosocial adjustment of foster care adoptees based on a scoping review of contributing factors. Clinical Psychologist, 22(1), 3-15. https://doi.org/10.1111/cp.12090.

Díaz, D., Rodríguez-Carvajal, R., Blanco, A., Moreno-Jiménez, B., Gallardo, I., Valle, C., et al. (2006). Adaptación española de las escalas de bienestar psicológico de Ryff. Psicothema, 18(3), 572-577.

Feeney, B. C., \& Collins, N. L. (2015). A new look at social support: A theoretical perspective on thriving through relationships. Personality and Social Psychology Review, 19(2), 113-147. https://doi. org/10.1177/1088868314544222.

Fuentes, M. C., Garcia, F., Gracia, E., \& Lila, M. (2011). Self-concept and drug use in adolescence. Adicciones, 23(3), 237-248. https://doi.org/10.20882/adicciones.148.

Garcia, O. F., Lopez-Fernandez, O., \& Serra, E. (2018). Raising Spanish children with an antisocial tendency: Do we know what the optimal parenting style is? Journal of Interpersonal Violence. https://doi. org/10.1177/0886260518818426.

Grant, K. E., Compas, B. E., Thurm, A. E., McMahon, S. D., Gipson, P. Y., Campbell, A. J., et al. (2006). Stressors and child and adolescent psychopathology: Evidence of moderating and mediating effects. Clinical Psychology Review, 26(3), 257-283. https://doi.org/10.1016/J.CPR.2005.06.011.

Grant, M., Rushton, A., \& Simmonds, J. (2016). Is early experience destiny? Review of research on longterm outcomes following international adoption with special reference to the British Chinese adoption study. The Scientific World Journal, 2016, 1-16. https://doi.org/10.1155/2016/6303490.

Greco, O., Rosnati, R., \& Ferrari, L. (2015). Adult adoptees as partners and parents: The joint task of revisiting the adoption history. Adoption Quarterly, 18(1), 25-44. https://doi.org/10.1080/10926 755.2014.895468. 
Greenfield, E. A., \& Marks, N. F. (2010). Identifying experiences of physical and psychological violence in childhood that jeopardize mental health in adulthood. Child Abuse and Neglect, 34(3), 161-171. https ://doi.org/10.1016/j.chiabu.2009.08.012.

Grotevant, H. D., Rueter, M., Von Korff, L., \& Gonzalez, C. (2011). Post-adoption contact, adoption communicative openness, and satisfaction with contact as predictors of externalizing behavior in adolescence and emerging adulthood. Journal of Child Psychology and Psychiatry and Allied Disciplines, 52(5), 529-536. https://doi.org/10.1111/j.1469-7610.2010.02330.x.

Grusec, J. E., \& Goodnow, J. J. (1994). Impact of parental discipline methods on the child's internalization of values: a reconceptualization of current points of view. Developmental Psychology, 30(1), 4-19. https://doi.org/10.1037/0012-1649.30.1.4.

Hartman, A., \& Laird, J. (1990). Family treatment after adoption: Common themes. In D. M. Brodzinsky \& M. D. Schechter (Eds.), The psychology of adoption (pp. 221-239). New York: Oxford University Press.

Herrenkohl, T. I., Jung, H., Klika, J. B., Mason, W. A., Brown, E. C., Leeb, R. T., et al. (2016). Mediating and moderating effects of social support in the study of child abuse and adult physical and mental health. American Journal of Orthopsychiatry, 86(5), 573-583. https://doi.org/10.1037/ort00 00136.

Hogan, B. E., Linden, W., \& Najarian, B. (2002). Social support interventions. Clinical Psychology Review, 22(3), 381-440. https://doi.org/10.1016/S0272-7358(01)00102-7.

Hogg, C., Rutter, M., \& Richman, N. (1997). Emotional and behavioural problems in children. Windsor, UK: NFER-Nelson Publishing Company.

Huebner, E. S. (1991). Further validation of the students' life satisfaction scale: The independence of satisfaction and affect ratings. Journal of Psychoeducational Assessment, 9(4), 363-368. https:// doi.org/10.1177/073428299100900408.

Jans-Beken, L., Lataster, J., Peels, D., Lechner, L., \& Jacobs, N. (2017). Gratitude, psychopathology and subjective well-being: Results from a 7.5-month prospective general population study. Journal of Happiness Studies. https://doi.org/10.1007/s10902-017-9893-7.

Juffer, F., van IJzendoorn, M. H., \& Palacios, J. (2011). Children's recovery after adoption. Infancia y Aprendizaje, 34(1), 3-18. https://doi.org/10.1174/021037011794390102.

Kalmakis, K. A., \& Chandler, G. E. (2015). Health consequences of adverse childhood experiences: A systematic review. Journal of the American Association of Nurse Practitioners, 27(8), 457-465. https://doi.org/10.1002/2327-6924.12215.

Kendall-Tackett, K. (2002). The health effects of childhood abuse: Four pathways by which abuse can influence health. Child Abuse and Neglect, 26(6-7), 715-729. https://doi.org/10.1016/S0145 -2134(02)00343-5.

Keresteš, G., Brković, I., \& Kuterovac Jagodić, G. (2012). Predictors of psychological well-being of adolescents' parents. Journal of Happiness Studies, 13, 1073-1089. https://doi.org/10.1007/s1090 2-011-9307-1.

Keyes, K. M., Eaton, N. R., Krueger, R. F., McLaughlin, K. A., Wall, M. M., Grant, B. F., et al. (2012). Childhood maltreatment and the structure of common psychiatric disorders. British Journal of Psychiatry, 200(2), 107-115. https://doi.org/10.1192/bjp.bp.111.093062.

Lee, R. D., \& Chen, J. (2017). Adverse childhood experiences, mental health, and excessive alcohol use: Examination of race/ethnicity and sex differences. Child Abuse and Neglect, 69(January), 40-48. https://doi.org/10.1016/j.chiabu.2017.04.004.

Levy-Shiff, R. (2001). Psychological adjustment of adoptees in adulthood: Family environment and adoption-related correlates. International Journal of Behavioral Development, 25(2), 97-104. https ://doi.org/10.1080/01650250042000131.

MacKinnon, D. P., Fairchild, A. J., \& Fritz, M. S. (2007). Mediation analysis. Annual Review of Psychology, 58, 593-614. https://doi.org/10.1146/annurev.psych.58.110405.085542.

Martínez, I., Garcia, F., Fuentes, M. C., Veiga, F., Garcia, O. F., Rodrigues, Y., et al. (2019). Researching parental socialization styles across three cultural contexts: Scale ESPA29 bi-dimensional validity in Spain, Portugal, and Brazil. International Journal of Environmental Research and Public Health, 16, 1-14. https://doi.org/10.3390/ijerph16020197.

McGoron, L., Gleason, M. M., Smyke, A. T., Drury, S. S., Nelson, C. A., Gregas, M. C., et al. (2012). Recovering from early deprivation: Attachment mediates effects of caregiving on psychopathology. Journal of the American Academy of Child and Adolescent Psychiatry, 51(7), 683-693. https://doi. org/10.1016/j.jaac.2012.05.004.

Melero, S., \& Sánchez-Sandoval, Y. (2017). Mental health and psychological adjustment in adults who were adopted during their childhood: A systematic review. Children and Youth Services Review, 77, 188-196. https://doi.org/10.1016/j.childyouth.2017.05.006. 
Murthi, M., \& Espelage, D. L. (2005). Childhood sexual abuse, social support, and psychological outcomes: A loss framework. Child Abuse and Neglect, 29(11), 1215-1231. https://doi.org/10.1016/j. chiabu.2005.03.008.

Nurius, P. S., Green, S., Logan-Greene, P., \& Borja, S. (2015). Life course pathways of adverse childhood experiences toward adult psychological well-being: A stress process analysis. Child Abuse and Neglect, 45, 143-153. https://doi.org/10.1016/j.chiabu.2015.03.008.

Oke, M., Groza, V., Park, H., Kalyanvala, R., \& Shetty, M. (2015). The perceptions of young adult adoptees in India on their emotional well-being. Adoption and Fostering, 39(4), 343-355. https://doi. org/10.1177/0308575915611776.

Palacios, J., Román, M., Moreno, C., León, E., \& Peñarrubia, M. G. (2014). Differential plasticity in the recovery of adopted children after early adversity. Child Development Perspectives, 8(3), 169-174. https://doi.org/10.1111/cdep.12083.

Riquelme, M., García, O. F., \& Serra, E. (2018). Psychosocial maladjustment in adolescence: Parental socialization, self-esteem, and substance use. Anales de Psicología, 34(3), 536-544. https://doi. org/10.6018/analesps.34.3.315201.

Rosenberg, M. (1965). Society and the adolescent self-image. Princeton, NJ: Princeton University Press.

Runtz, M. G., \& Schallow, J. R. (1997). Coping strategies, social support, and recovery from physical and sexual maltreatment during childhood. Child Abuse and Neglect, 21(2), 211-226.

Ryff, C. D. (1989). Happiness is everything, or is it? Journal of Personality and Social Psychology, 57(6), 1069-1081. https://doi.org/10.1037/034645.

Ryff, C. D. (2014). Psychological well-being revisited: Advances in the science and practice of eudaimonia. Psychotherapy and Psychosomatics, 83(1), 10-28. https://doi.org/10.1159/000353263.

Ryff, C. D., \& Keyes, C. L. M. (1995). The structure of psychological well-being revisited. Journal of Personality and Social Psychology, 69(4), 719-727. https://doi.org/10.1037/0022-3514.69.4.719.

Sánchez-Sandoval, Y. (2002). El ajuste de niños y niñas adoptados y su vida familiar: un estudio longitudinal. Unpublished Doctoral Disertation. Universidad de Sevilla.

Sánchez-Sandoval, Y. (2011). Satisfacción con la adopción y con sus repercusiones en la vida familiar. Psicothema, 23(4), 630-635.

Sánchez-Sandoval, Y. (2015). Self-perception, self-esteem and life satisfaction in adopted and non-adopted children and adolescents. Infancia y Aprendizaje, 38(1), 144-174. https://doi.org/10.1080/02103 702.2014.996406.

Sánchez-Sandoval, Y., \& Palacios, J. (2012). Stress in adoptive parents of adolescents. Children and Youth Services Review, 34(7), 1283-1289. https://doi.org/10.1016/j.childyouth.2012.03.002.

Schulenberg, J. E., Sameroff, A. J., \& Cicchetti, D. (2004). The transition to adulthood as a critical juncture in the course of psychopathology and mental health. Development and Psychopathology, 16, 799-806. https://doi.org/10.1017/S0954579404040015.

Segatto, B., \& Ben, A. D. (2013). The recovery function of adoption. A study carried out in the Italy's Veneto region. Interdisciplinary Journal of Family Studies, 18(2), 98-113. https://doi.org/10.14658/ ijfs-18-2.

Steinberg, L. (2001). We know some things: Parent-adolescent relationships in retrospect and prospect. Journal of Research on Adolescence, 11(1), 1-19. https://doi.org/10.1111/1532-7795.00001.

Tan, C. S., Low, S. K., \& Viapude, G. N. (2018). Extraversion and happiness: The mediating role of social support and hope. PsyCh Journal, 7, 133-143. https://doi.org/10.1002/pchj.220.

Taylor, Z. E., Doane, L. D., \& Eisenberg, N. (2014). Transitioning from high school to college: Relations of social support, ego-resiliency, and maladjustment during emerging adulthood. Emerging Adulthood, 2(2), 105-115. https://doi.org/10.1177/2167696813506885.

Uchino, B. N. (2009). Understanding the links between social support and physical health of perceived and received support. Psychological Science, 4(3), 236-255. https://doi.org/10.111 1/j.1745-6924.2009.01122.x.

van der Vegt, E. J. M., van der Ende, J., Ferdinand, R. F., Verhulst, F. C., \& Tiemeier, H. (2009). Early childhood adversities and trajectories of psychiatric problems in adoptees: Evidence for long lasting effects. Journal of Abnormal Child Psychology, 37(2), 239-249. https://doi.org/10.1007/s10802-008-9272-2.

van Dierendonck, D., Díaz, D., Rodríguez-Carvajal, R., Blanco, A., \& Moreno-Jiménez, B. (2008). Ryff's six-factor model of psychological well-being, a Spanish exploration. Social Indicators Research, 87, 473-479. https://doi.org/10.1007/s11205-007-9174-7.

Westermeyer, J., Yoon, G., Tomaska, J., \& Kuskowski, M. A. (2014). Internalizing disorder in adopted versus non-adopted adults: A NESARC based study. Comprehensive Psychiatry, 55(7), 1595-1600. https ://doi.org/10.1016/j.comppsych.2014.05.014. 
Zhou, Q., Zhang, J., \& Hennessy, D. A. (2018). The role of family absolute and relative income in suicide among Chinese rural young adults: Mediation effects of social support and coping strain. Journal of Public Health. https://doi.org/10.1093/pubmed/fdy123.

Publisher's Note Springer Nature remains neutral with regard to jurisdictional claims in published maps and institutional affiliations. 